Article

\title{
Battery Design for Successful Electrification in Public Transport
}

\author{
Susanne Rothgang 1,2,*, Matthias Rogge 1,2, Jan Becker ${ }^{1,2}$ and Dirk Uwe Sauer 1,2,3
}

1 Institute for Power Electronics and Electrical Drives (ISEA), RWTH Aachen University, Jägerstr. 17/19, 52066 Aachen, Germany; E-Mails: mar@isea.rwth-aachen.de (M.R.); jab@isea.rwth-aachen.de (J.B.); rg@isea.rwth-aachen.de (D.U.S.)

2 Jülich Aachen Research Alliance, JARA-Energy, 52425 Jülich, Germany

3 Institute for Power Generation and Storage Systems (PGS), E.ON Energy Research Center, RWTH Aachen University, Mathieustr. 10, 52074 Aachen, Germany

* Author to whom correspondence should be addressed; E-Mail: batteries@isea.rwth-aachen.de; Tel.: +49-241-809-6977; Fax: +49-241-809-2203.

Academic Editor: Paul Stewart

Received: 24 April 2015 / Accepted: 19 June 2015 / Published: 30 June 2015

\begin{abstract}
Public transport is an especially promising sector for full electric vehicles due to the high amount of cycles and predictable workload. This leads to a high amount of different vehicle concepts ranging from large batteries, designed for a full day of operation without charging, to fast-charging systems with charging power up to a few hundred kilowatts. Hence, many different issues have to be addressed in the whole design and production process regarding high-voltage (HV) batteries for buses. In this work, the design process for electric public buses is analyzed in detail, based on two systems developed by the research projects Smart Wheels/econnect and SEB eÖPNV. The complete development process starting, with the demand analysis and the operating scenario, including the charging routine, is discussed. This paper also features details on cell selection and cost estimations as well as technical details on the system layout, such as the management system and passive components as well as thermal management.
\end{abstract}

Keywords: batteries; electric vehicles; public transport; layout process 


\section{Introduction}

Currently, all large vehicle manufacturers are gradually electrifying their fleets either with full (BEV) or hybrid electric vehicles (HEV) to meet the new European $\mathrm{CO}_{2}$ emission regulations for 2015 and 2020 [1]. This results in new requirements for batteries. At the same time, batteries will remain the most expensive components of the vehicles for the next 10 to 20 years, though battery cell costs have been rapidly decreasing recently [2]. Cycle lifetimes of up to 1000 cycles at a depth of discharge (DoD) of $80 \%$ are needed for passenger vehicles [3]. An average vehicle lifetime of about 12 years in Germany defines the needed calendric lifetime. Aging studies such as [4] show that the cycle lifetime of automotive cells is more than sufficient to fulfill these passenger vehicle requirements. Moreover, in the currently available vehicles, a relatively large driving range is guaranteed. The BMW i3 for example is designed for up to $150 \mathrm{~km}$ pure electric driving, and the Tesla Model S promises even a maximum driving range of up to $480 \mathrm{~km}$ to meet customers' range needs. At the same time, the battery capacity actually used is comparatively low; $95 \%$ of all single drives in Germany are, for example, shorter than $42 \mathrm{~km}$ [5] and the average daily driven mileage in the United Kingdom is only around $40 \mathrm{~km} \mathrm{[6].} \mathrm{Hence,}$ a good part of the battery remains mostly unused, resulting in second use concepts for grid stabilization (see e.g., [7-9]) in order not to waste the expensive systems due to calendric aging. Calendric aging occurs no matter whether the battery is cycled or not $[4,10]$.

As for the situation for electric buses in public transport, here, the daily mileage as well as the load is precisely known for each respective bus route. Moreover, the average annual usage is, in Germany for example, with 50,000 km [11] and a vehicle lifespan of 12 years, significantly more demanding than for conventional passenger vehicles. In an example system explained later on, the equivalent full cycles per year are 1200 . Hence, the battery cells are effectively used regarding their possible cycle lifetime. This makes public transport the most promising sector for economic benefit from electrified vehicles in the near future.

This paper will therefore provide insight into the complete development process of an electric public transport bus. It will start with an introduction about the development process itself. In the first main step a typical usage profile and a suitable reference system will be introduced. Based on this, possible system layouts and charging regimes will be discussed and compared with each other, also highlighting existing systems on the market. This will be followed by important design choices such as the topology within the battery and its monitoring system. Moreover, the passive components and thermal management needed for a reliable battery system will be addressed, taking the available mounting space, volume and costs into account. In that discussion, experience gained from two developed prototype systems will be exploited for further details. In the research project "Smart Wheels," a small inner-city bus was electrified (Mercedes Benz Sprinter City 65). In "SEB eÖPNV" a standard $12 \mathrm{~m}$ low floor bus is electrified and equipped with a fast charging system of up to 500 kilowatts.

\section{Steps in the Development of Electric Buses}

With cities already paying extra money for their public transport systems, the success of electric buses requires aiming for minimal life cycle costs (LCC) in order to be competitive with diesel buses. This can only be achieved by choosing components, especially the battery system, through a structured 
design process. In Figure 1 the general steps in the development process are shown, and they will be explained in more detail in later sections.

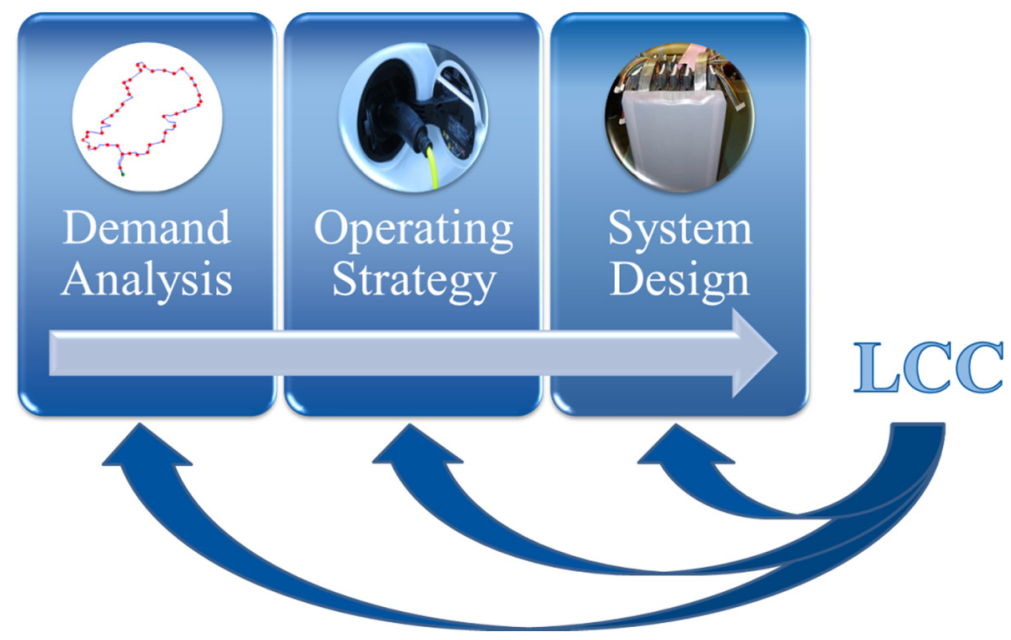

Figure 1. Steps in the development process of an electric bus.

Several assumptions have to be made when calculating the LCC of buses. The main parameters that should be considered for diesel and electric buses are given in Table 1. Moreover, ISEA provides an online tool to estimate the LCC costs based on parameters introduced below, so that it can be run for different configurations during the demand analysis, and on choosing an operating strategy [12]. As the operating scenario, a usage period of 12 years with an annual mileage of $50,000 \mathrm{~km}$ shall be considered according to the numbers given in section 1 . An interest rate of $4 \%$ is assumed. Regarding the inflation rate, especially for electric buses, a higher market penetration in the future has to be assumed. Hence, different inflation rates for diesel and electric buses should be used. The overall maintenance costs of electric buses will be less for electric vehicles due to the low-maintenance electric machine, less braking effort and no oil changes. However, they will strongly depend on the installed infrastructure and charging technique. Using these parameters, a comparison of an electric to a diesel bus can be done assuming a battery size of 90 kilowatt-hours as was installed in the SEB bus. Parameterized by these data, an electric bus would be more expensive within the first 7 years due to the high investment costs but become cheaper than a diesel bus in the following years due to the high cost-saving potential compared to high diesel costs. The costs per kilometer for diesel buses rise from 1.27 Euros per kilometer in the first year up to 1.78 Euros per kilometer in the 12 year. Electric buses in this configuration, in contrast, have higher initial costs of 1.64 Euros per kilometer, which decline in the following years to 1.48 Euros per kilometer in year 12. Hence, it can be seen that electric buses are potentially competitive with diesel buses in terms of total cost of ownership. At the same time it is obvious that this strongly depends on the costs for the battery systems and their lifetime, as they are the main cost-pusher for electric buses. In Table 2 the influence of the battery size on the costs per kilometer is shown in order to emphasize this fact.

Therefore, within the demand analysis, detailed knowledge of the expected energy consumption as well as the needed peak driving power of the specific bus route has to be obtained in order to size the battery appropriately. As also shown by [13] it is not sufficient to use a standard drive cycle but rather the real operation scenarios and their occurrence probability [14]. Based on that, the operating strategy 
can be selected, taking the effort for the infrastructure as well as the boundary conditions of the chosen vehicle type into account. The electrical, mechanical and thermal development have to take place in the system design process. Life cycle costs have to be taken into account during all steps, allowing for feedback loops if a prior decision turns out not to result in a cost-optimized system.

Table 1. LCC parameters for electric $(90 \mathrm{kWh})$ and diesel buses.

\begin{tabular}{|c|c|c|c|c|}
\hline Parameter & \multicolumn{2}{|c|}{ Diesel } & \multicolumn{2}{|c|}{ Electric } \\
\hline \multirow{3}{*}{ Acquisition costs } & \multirow{3}{*}{\multicolumn{2}{|c|}{$240,000 €$ bus }} & \multicolumn{2}{|c|}{$300,000 €$ bus (without battery) } \\
\hline & & & \multicolumn{2}{|c|}{$800 € \cdot \mathrm{kW} / \mathrm{h}$ battery } \\
\hline & & & \multicolumn{2}{|c|}{$225,000 €$ charging infrastructure } \\
\hline \multirow{4}{*}{$\begin{array}{l}\text { Residual value \& } \\
\text { multiuse }\end{array}$} & \multirow{4}{*}{$12,000 €$} & \multirow{4}{*}{12 years } & $15,000 €$ bus & 12 years \\
\hline & & & $0 €$ battery & 5 years \\
\hline & & & $4500 €$ infrastructure & 20 years \\
\hline & & & $\begin{array}{l}\text { Charging infrastructure can be us } \\
\text { only calculate the infrastructur } \\
\text { e.g., } 5 \text { buses with a charging stati }\end{array}$ & $\begin{array}{l}\text { or several buses/lines } \\
\text { sts proportionally in } \\
\text { t each end of the line }\end{array}$ \\
\hline $\begin{array}{c}\text { Diesel/Electricity costs } \\
\text { and price increase }\end{array}$ & $1.2 € / \mathrm{L}$ & $\begin{array}{c}6.1 \% / a \\
\text { (Germany) }\end{array}$ & $0,15 € / \mathrm{kWh}$ & $3.2 \% / a$ (Germany) \\
\hline \multirow{3}{*}{ Inflation rates } & \multirow{3}{*}{\multicolumn{2}{|c|}{$2 \%$}} & \multicolumn{2}{|l|}{$-3 \%$ bus } \\
\hline & & & \multicolumn{2}{|c|}{$-12 \%$ battery (see section 3.2 ) } \\
\hline & & & \multicolumn{2}{|c|}{$0 \%$ infrastructure } \\
\hline $\begin{array}{c}\text { Maintenance and } \\
\text { additional costs }\end{array}$ & \multicolumn{2}{|c|}{$15,000 € / \mathrm{a}$} & \multicolumn{2}{|c|}{ Depending on installed infrastructure } \\
\hline Consumption & \multicolumn{2}{|c|}{$40 \mathrm{~L} / 100 \mathrm{~km}$} & \multicolumn{2}{|c|}{$152 \mathrm{kWh} / 100 \mathrm{~km}$} \\
\hline Efficiency & \multicolumn{2}{|c|}{-} & \multicolumn{2}{|c|}{$90 \%$ battery $93 \%$ charging infrastructure } \\
\hline
\end{tabular}

Table 2. Price per kilometer development for diesel and electric buses taking all above explained costs into account and showing the impact of battery costs on the overall costs per kilometer.

\begin{tabular}{ccccccccccccc}
\hline Bus Type & $\mathbf{1}$ & $\mathbf{2}$ & $\mathbf{3}$ & $\mathbf{4}$ & $\mathbf{5}$ & $\mathbf{6}$ & $\mathbf{7}$ & $\mathbf{8}$ & $\mathbf{9}$ & $\mathbf{1 0}$ & $\mathbf{1 1}$ & $\mathbf{1 2}$ \\
\hline Diesel $(€ / \mathrm{km})$ & 1.27 & 1.30 & 1.34 & 1.38 & 1.42 & 1.47 & 1.51 & 1.56 & 1.61 & 1.66 & 1.72 & 1.78 \\
Electric $90 \mathrm{kWh}(€ / \mathrm{km})$ & 1.64 & 1.64 & 1.65 & 1.66 & 1.66 & 1.52 & 1.52 & 1.53 & 1.54 & 1.55 & 1.48 & 1.48 \\
Electric $180 \mathrm{kWh}(€ / \mathrm{km})$ & 1.96 & 1.97 & 1.97 & 1.98 & 1.99 & 1.69 & 1.69 & 1.70 & 1.71 & 1.72 & 1.57 & 1.57 \\
\hline
\end{tabular}

\section{System Layout Options}

Table 3 gives the important parameters of a $12 \mathrm{~m}$ full electric public transport bus, which is used in SEB eÖPNV. Moreover, the parameters of the Smart Wheels inner city bus are given. While the SEB bus is a standard public transport vehicle and therefore of interest for all routes, the Smart Wheels bus is designed for use cases such as operation in narrow streets in old city centers as well as shuttle operation. Figure 2 shows the two busses.

Based on these parameters a vehicle model can be parameterized to calculate the energy demand. The main auxiliaries have to be approximated depending on whether the full bus is electrically heated or only contains an air-conditioned driver's cabin. This results in a range of 4.5 to 20 kilowatts of 
auxiliary loads. Hence, the heating and cooling concept has an enormous impact on the continuous energy consumption and must be considered during system design.

Table 3. Reference system for a $12 \mathrm{~m}$ full electric bus used to calculate the energy consumption on different bus routes.

\begin{tabular}{ccc}
\hline Parameter & Reference Bus (SEB) & Smart Wheels \\
\hline width & $2.55 \mathrm{~m}$ & $1.99 \mathrm{~m}$ \\
height & $3.2 \mathrm{~m}$ & $2.71 \mathrm{~m}$ \\
length & $12 \mathrm{~m}$ & $7.02 \mathrm{~m}$ \\
average time at bus stop & \multicolumn{2}{c}{$0.5 \mathrm{~min}$} \\
max. driving power & $200 \mathrm{~kW}$ & $120 \mathrm{~kW}$ \\
admissible total weight & $18,000 \mathrm{~kg}$ & $6,650 \mathrm{~kg}$ \\
drag coefficient & \multicolumn{3}{c}{0.66} \\
rolling friction & \multicolumn{3}{c}{$0.013 \mathrm{~m} / \mathrm{s}^{2}$} \\
ratio between mechanical to electrical breaking system & \multicolumn{3}{c}{0.5} \\
drivetrain efficiency & \multicolumn{3}{c}{$90 \%$} \\
average battery efficiency & \multicolumn{3}{c}{$\mathbf{c}$} \\
\hline
\end{tabular}

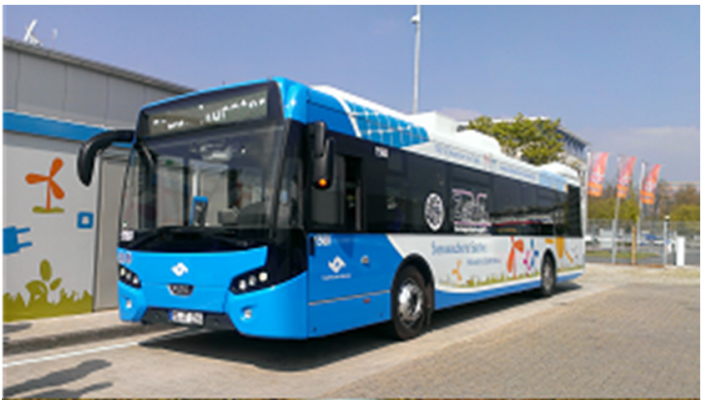

(a)

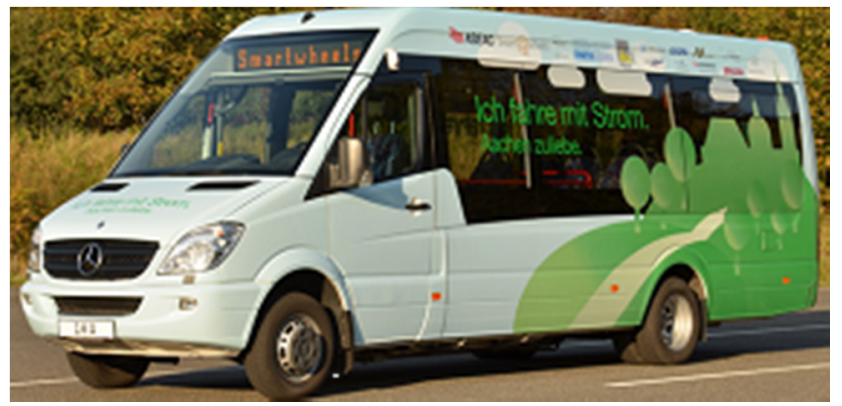

(b)

Figure 2. SEB bus (a) with $500 \mathrm{~kW}$ charging infrastructure and (b) Smart Wheels inner city bus.

\subsection{Estimating the Energy Demand of the Bus Route}

A Matlab/Simulink R2013b tool, which was developed at the institute, was used to estimate the energy consumption for a reference bus route. Detailed information on it can be found in [15]. Figure 3 shows the structure of the tool. As measurement data on the speed and height profile might not be available for all routes, synthetic profiles are generated using internet map services. Next to the accurate driving route the bus stops are also added. Depending on the actual time table, the waiting period is set to at least $15 \mathrm{~s}$. The maximum inner-city speed is set to $50 \mathrm{~km}$ per hour. Moreover, additional stops at traffic lights or crossings are included randomly.

As internet map services usually do not contain detailed height information, elevation data is obtained from the Shuttle Radar Topography Mission (SRTM) database. Additionally to the track data, vehicle parameters (Table 3) have to be set and the boundary conditions such as weather and occupancy rate have to be chosen. The weather condition influences the power of the auxiliary devices whereas the occupancy rate defines the total weight of the bus. Based on the estimated profile, the vehicle 
parameters, and the assumed boundary conditions, a full vehicle simulation was run in Matlab/Simulink to estimate the average and maximum energy consumption during one round.

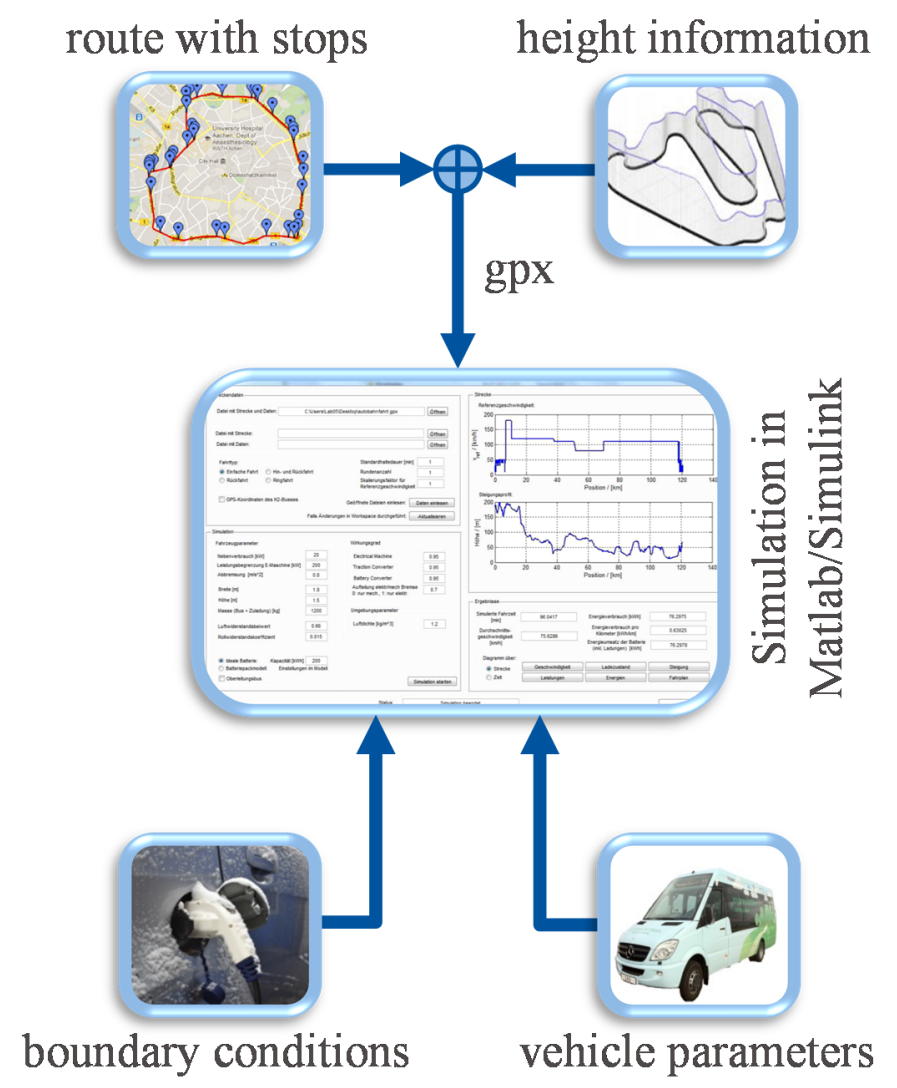

Figure 3. Matlab/Simulink tool for the demand analysis of the bus route using Google Maps for route planning based on the gpx (xml format for storing coordinate data) data.

According to the explained routine, bus route 14 of the bus network in Münster, Germany was simulated for the layout of the SEB bus. Figure 4 shows the resulting speed profile as well as the correlated energy consumption of the bus route for a fully occupied bus without an electrical heating system. It shows a total consumption for traction as well as auxiliaries of over 20 kilowatt-hours per round. Due to the high amount of stops almost 30 percent can be recuperated leading to an overall energy demand of 1.52 kilowatt-hours per kilometer. The daily load can be calculated and used to choose an operating strategy based on these consumption data.

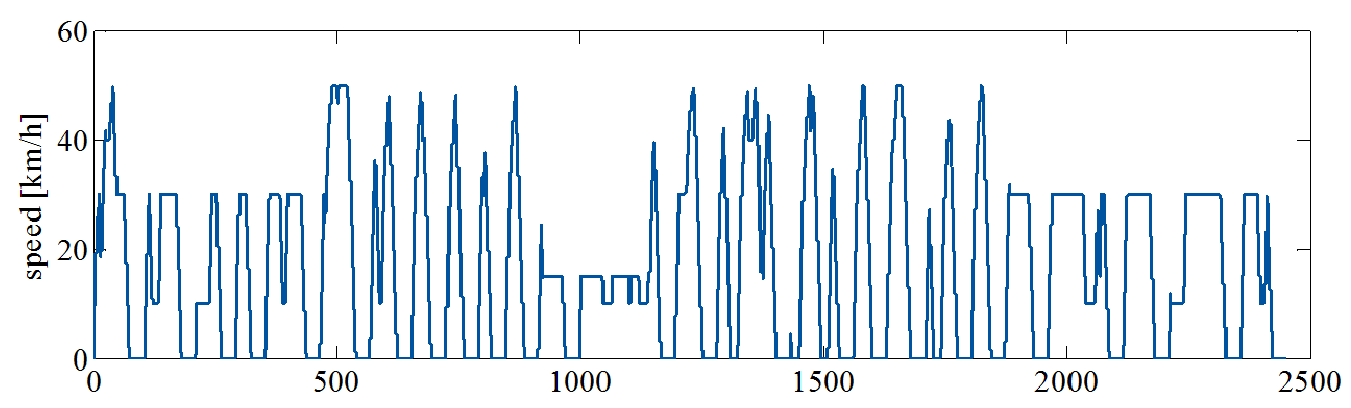

(a)

Figure 4. Cont. 


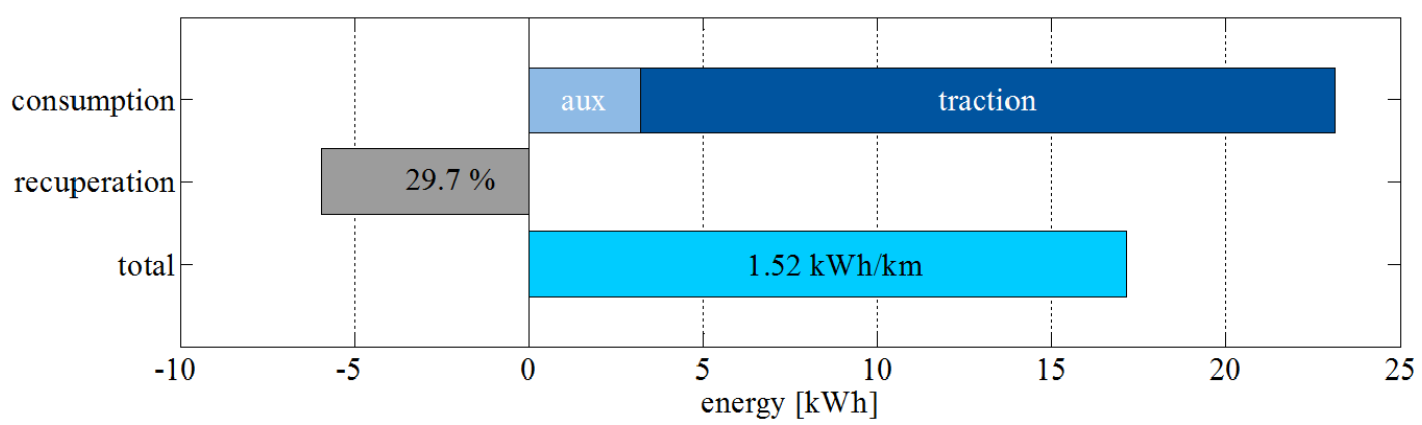

(b)

Figure 4. Speed profile and energy consumption of bus route 14 in Münster.

\subsection{Operating Strategy}

Knowing the energy demand of the bus route an operating strategy can be chosen. Table 4 gives an overview of the possible strategies as well as their pros and cons, which will be discussed more in detail below.

Table 4. Possible operating strategies and their pros $(+)$ and cons $(-)$.

\begin{tabular}{ccccccc}
\hline Strategy & $\begin{array}{c}\text { Infrastructure } \\
\text { Effort }\end{array}$ & $\begin{array}{c}\text { Charging } \\
\text { Power }\end{array}$ & DoD & $\begin{array}{c}\text { Battery Size, } \\
\text { Weight and Costs }\end{array}$ & Flexibility & Complexity \\
\hline $\begin{array}{c}\text { overnight charging } \\
\text { fast charging at intermediate stops }\end{array}$ & + & + & - & - & - & + \\
fast charging at final stops & - & - & + & + & - & - \\
\hline
\end{tabular}

The main difference can be seen in either operating the bus without recharging in service or with an intermediate charging using a high charging power. Electric buses from China are often equipped with a battery providing enough energy for full-day operation. An example for this is the BYD K9 [16] which is also exported to Europe. The system architecture of a full day operating bus is in general easier compared to fast charging concepts as e.g., the cooling demand for the battery system is lower due to the reduced peak power. In addition to that, no expensive charging infrastructure is needed. Thus, such a concept provides the highest flexibility within scheduling. The battery can be charged overnight using only a moderate charging power, which is beneficial with regard to battery lifetime. High charging powers have negative impacts on battery aging that must not be neglected [17]. Moreover, standard charging also limits the maximum amperage at the cell level. In that case, it is determined by the highest driving power instead of possibly needing higher charging power in the fast charging strategy. This leads at the same time to a higher gravimetric and volumetric energy density. In comparison to high power (HP) cells, high energy (HE) cells have thicker layers of active material and therefore also a higher energy density [18], which is superior to other battery technologies [19,20].

However, there are also several drawbacks for the overnight charging concept that have to be taken into account. First of all the needed energy content for a full day of operation results in a very large battery system in the range of 200-400 kilowatt-hours. This limits, in a worst-case scenario, the possible payload of the buses. Currently a gravimetric energy density of around 100 watt-hours per kilogram can be achieved for state-of-the-art battery systems [21]. For the shown reference bus route with 20 trips per 
bus per day, an overall energy content of 307 kilowatt-hours would be needed if the bus is only charged overnight. The impact of this can also be shown by the system in the research project Smart Wheels. The used vehicle has an admissible total weight of 5650 kilograms. The demand analysis showed that a minimum energy content of 120 kilowatt-hours would be needed to fulfill the full-day operation at the desired circular route in Aachen. However, this would lead to a battery system weight of at least 1100 kilograms and therefore one fifth of the overall admissible total weight [22] which equals a reduction of the passenger load by $30 \%$. This is, of course, unacceptable, so recharging during operation is mandatory in that case. This was achieved by recharging en route with 60 kilowatts. Compared to the average driving power of approximately 18 kilowatts, the maximum charging power is distinctively higher and therefore the key factor on system layout.

Secondly, the batteries have to be cycled with a high depth of discharge (DoD) in the overnight charging strategy which might enhance aging compared to smaller cycles. As in fast charging only smaller batteries are needed anyways, the cycle depth can be limited without a too huge influence on system weight and cost. This, however, has to be analyzed for each cell and usage condition (cycle depth full day operation vs. cycle depth with intermediate charging) individually. Ecker et al. for example found a great impact from the cycle depth for an investigated cell of $\mathrm{Li}(\mathrm{NiMnCo}) \mathrm{O}_{2}$ [10] whereas Wang et al. on the other hand found no influence at all for an investigated $\mathrm{LiFePO}_{4}$ material [23]. Hence, when designing a bus without charging en route, it is mandatory to analyze the cell's aging in detail in order to choose a cell that shows no huge dependency on cycle depth and to consider a slight over-dimensioning in order to reduce the cycle depth. Moreover, it has to be emphasized once again at that point that the higher charging power also has a negative impact on battery lifetime. Therefore, in strategy optimization, a trade-off between these factors has to be found depending on the used cells' aging characteristics.

Finally, large battery systems come at a high cost. Fast charging during operation can reduce the required battery capacity tremendously, leading to reduced vehicle investment costs. Cost estimations for Li-ion cells in 2020 range from 200 Euros per kilowatt-hour (Roland Berger) to over 140 Euros per kilowatt-hour (European Council for Automotive R\&D-EUCAR) down to only 77 Euros per kilowatt-hour (United States Council for Automotive Research-USCAR) [24] and the system price scales directly with the cell costs. Tesla already nowadays claims its system price to be around 180 Euros per kilowatt-hour. A corresponding battery price drop from currently 330 Euros per kilowatt-hour to 180 Euros per kilowatt-hour on pack level in the private car sector is estimated until 2020 [25]. Therefore, system costs will be reduced a great deal compared to current systems, which can be estimated to be in the range of 600 to 800 Euro per kilowatt-hour in the public transport sector. However, in contrast to electric passenger cars, no huge economy of scale effects are expected in the public transport sector on system level. The new registrations rate is only around 33,000 buses per year in Western Europe [26]. Of these buses, around 35\% account for the public transport sector whereas the rest of the buses are long distance travel [27] which are not of interest in this matter. Therefore, around 11,000 new buses are registered per year in Western Europe. This leads to an installed battery amount of approximately 220 megawatt-hours if 20 percent are fully electrified, with the constraint that a lot of different system architectures are needed to fulfill the specific route demand. In comparison a 20 percent electrification of the private car sector which is estimated by [25] (including plug-in hybrids) would mean an installed battery capacity of 36 gigawatt-hours. In this assumption, 15 million new registered 
cars in Western Europe per year and an estimated average battery capacity of 12 kilowatt-hours are considered. Therefore, a system price of 2.1 times the current cell price in the automotive sector is assumed as a realistic scenario for the transport sector, mainly driven by the price drop at the cell level. This would result in system costs below 400 Euros per kilowatt-hour. For intermediate charging, several different fast charging strategies are possible and shall be explained below. All of these have in common that, in addition to the impact on the drivetrain components, the impact on the grid and the energy price structure for the different charging regimes have to be considered [28,29].

Charging en route is currently realized by two different strategies. It can either be charged at the final stops of bus routes for a longer period or at several or even all intermediate stops for a very short period. Both strategies use already existing stops. Hence, no negative influence on the cycle times exists. On charging, either the fully consumed energy or only part of it can be recharged. The latter results in a depleting SoC (state of charge) during operation as can be seen in Figure 5, which depicts a strategy comparison for Smart Wheels.

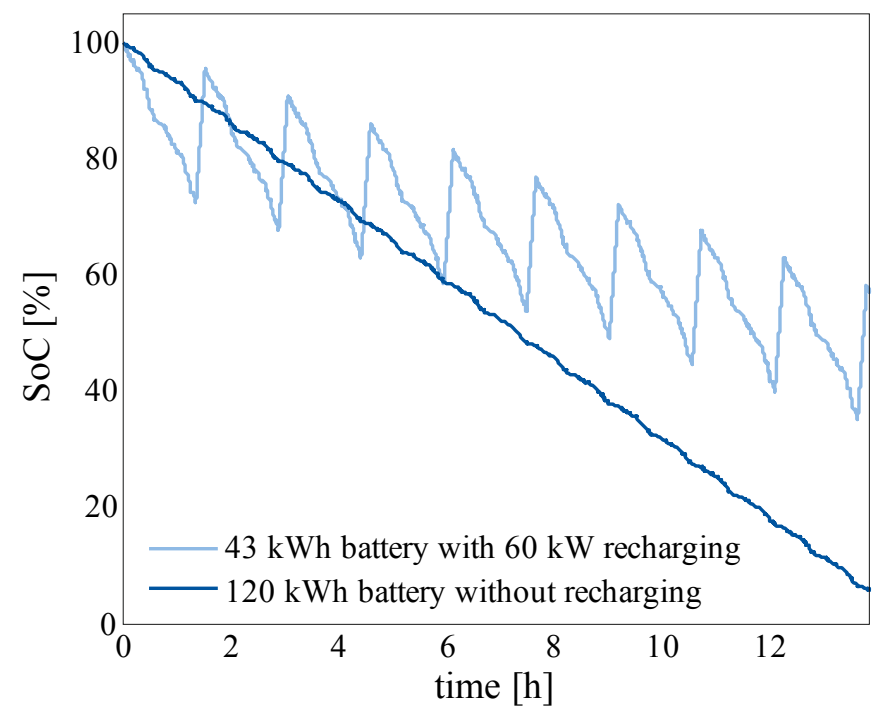

Figure 5. Comparison of operation without recharging and recharging with a depleting SoC during operation.

Recharging at each bus stop mainly involves inductive charging or charging via catenary as there is rarely enough time for automated plugging at bus stops. Hence, most of the time, the inductive charging station is directly inserted in the bus stop. The most popular example for this concept is the "primove" system from Bombardier [30]. Regarding pantograph systems especially, potentially existing electric tram or trolley bus systems within the cities can be taken into account to minimize the effort for the infrastructure tremendously [31]. As there are several common voltage levels up to 800 volts for tram catenaries, it has to be ensured that it is applicable for the bus voltage system. Examples for a catenary system are the System Electric Bus Rapid Transit from Siemens [32] and the multipole design charging pantographs of Schunk [33]. The connection to an existing DC (direct current) system results in greater flexibility as no huge infrastructure adaptations are needed, at the cost of greater complexity and weight at the bus side because chargers have to be installed in every vehicle. Therefore, this can be especially favorable for a small electric bus fleet if investment in the charging infrastructure would otherwise not pay back. Without the possibility of an existing DC feeding system, the grid connection especially is a 
cost-driving factor that needs to be considered carefully due to the required installation power that will not be available at a decent price at all bus stops.

\section{System Design}

Having decided on a charging strategy and therefore on the needed energy content of the battery, the system design process can be initiated. The left-hand side of Figure 6 shows a general overview of the components of a battery system that will be explained more in detail in the following. Moreover, in the right-hand side of Figure 6, a picture of the Smart Wheels' pack is given as a real life example. Different topologies are possible depending on the desired output voltage and the chosen cells [34]. Most of the current battery systems are built with a simple, strictly serial connection. However, there are also reasons to favor a more complex topology that connects smaller cells in parallel either on cell (parallel-series connection) or string level (serial-parallel) or consists of more than one pack.

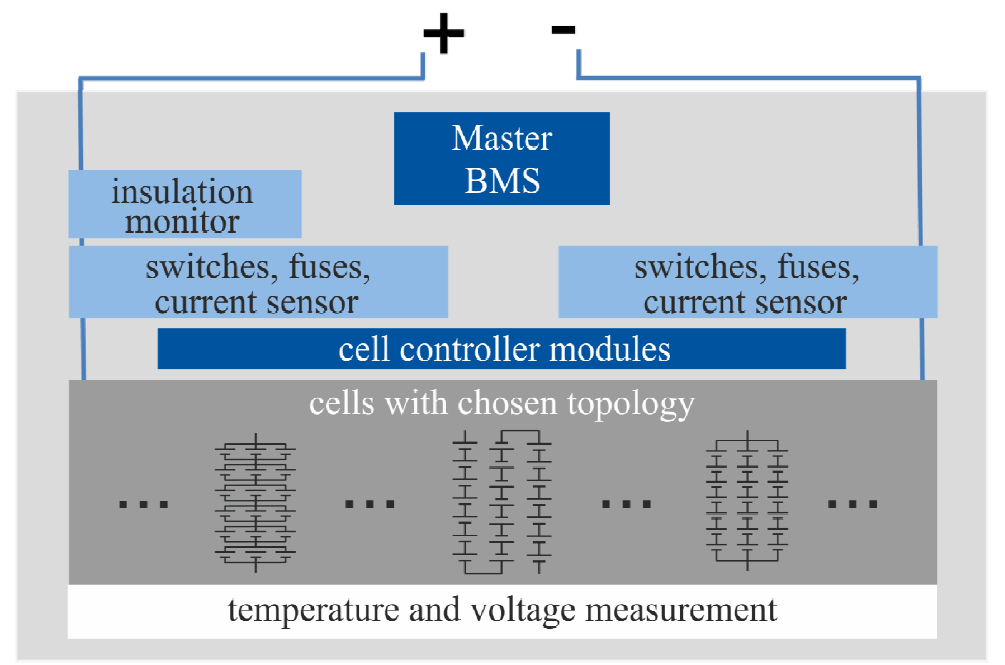

(a)

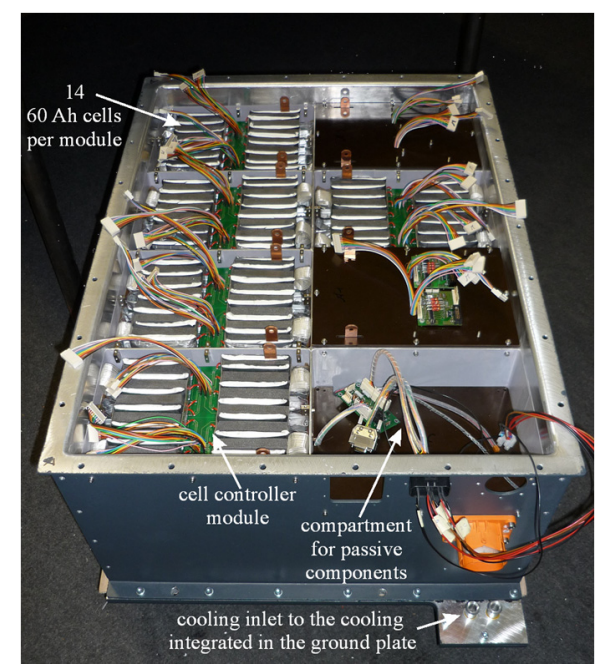

(b)

Figure 6. Layout of a battery system: Schematic structure (a) and Smart Wheels pack (b).

By connecting more cells in parallel, the redundancy is enhanced as a single cell fault does not necessarily lead to a failure of the complete system. Moreover, there is always a spread in the aging of the single cell capacities as shown in [35]. This can be statistically lowered by building the mean over several cells in a parallel connection [21]. With two independent packs the operation can be continued also in case of an error such as a too high temperature in one of the systems. This can be achieved either by connecting two identical packs directly in parallel or by connecting the packs via dc-to-dc converters to a common dc-link as shown in Figure 7. The latter offers the highest flexibility as two completely different packs can be used and it is possible to have unsymmetric loads on the packs [21]. If one DC-to-DC converter per pack is used as shown in the lowest scheme in Figure 7 the DC-link voltage is adjustable. This offers further flexibility in the drivetrain design at the cost of a higher complexity due to the additional power electronics and control effort. In the research projects used as references here, the packs were connected directly in parallel to enable at least a limp-home mode but limit the additional effort at the same time. 


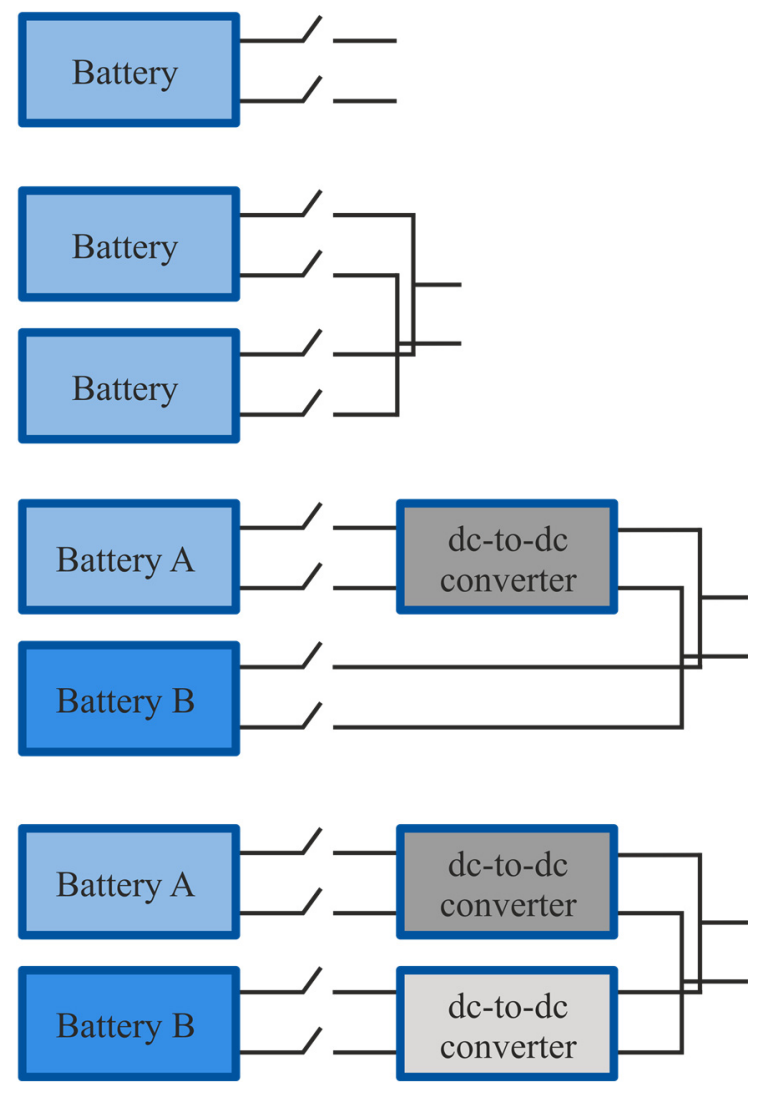

Figure 7. Topologies for batteries in automotive applications.

A further benefit of a distributed architecture is that the packs can be installed more easily outside the crash zones of the vehicles. This way, harmful deformation of the single cells can be prevented without the need for a strong housing for the batteries. If an installation outside the crash zones is not possible for a given vehicle type, further architectures can be considered that e.g., make the cell modules crash-resistant to absorb the energy in case of an accident. This was, for example, done within the research project e performance [36].

The voltage level of the system is defined by the internal connection of the cells. If a topology without DC-link is chosen, the battery voltage sets the voltage level of the traction inverter at the same time. Therefore, many of today's electric public transport buses are designed with a voltage of 700 to 800 volts as the needed driving power is also quite high and standard electronic components from the industry sector can be used in the converters. Moreover, it is the voltage already used for trolley buses and therefore further components are already on the market from this application as well.

\subsection{Cell Selection}

As already stated beforehand, the load profile in public buses can be predicted quite well. Hence, it is important to select a cell that best meets the specific requirements depending on the chosen operating strategy. Influencing factors are the chemistry, the estimated cycle depth, the charging strategy, and due to that, the peak power and the cooling demand. In Table 5 an overview of the most promising chemistries for public transport and their pros and cons are shown. 
Table 5. Comparison of Li-ion battery chemistries with potential interest for public transport $(\operatorname{good}(+)$, poor $(-)$, neutral $(\circ))$.

\begin{tabular}{ccccccc}
\hline \multirow{2}{*}{ Chemistry } & $\begin{array}{c}\text { Energy } \\
\text { Density }\end{array}$ & $\begin{array}{c}\text { Admissible Charging } \\
\text { Power }\end{array}$ & $\begin{array}{c}\text { Cycle } \\
\text { Lifetime }\end{array}$ & $\begin{array}{c}\text { Voltage } \\
\text { Curve }\end{array}$ & $\begin{array}{c}\text { Deep Temperature } \\
\text { Behavior }\end{array}$ & Safety \\
\hline NMC & + & $\circ$ & + & + & - & 0 \\
LFP & - & $\circ$ & + & - & - & + \\
LTO & - & + & ++ & - & + & + \\
\hline
\end{tabular}

The different li-ion cell types are usually named by their cathode material as the anode material is classically carbon-based, such as graphite or hard carbons [37]. An exception with a new anode material is lithium titanium oxide (LTO) cells that are of potential interest in public transport due to their superior cycle lifetime, high power capability during charging [38] and good deep temperature behavior at the cost of lower voltage and therefore lower energy density compared with standard materials. The deep temperature behavior is of particular interest for public transport as recharging also has to be possible at deep temperatures. This is true for LTO as, in contrast to the conventional anode materials, lithium plating cannot occur. The lack of the risk of lithium plating is also the reason for the high admissible charging powers. Yet, this also depends on the internal structure of the cell. The four basic materials used on the cathode side are lithium cobalt oxide (LCO), lithium nickel oxide (LNO), spinel lithium manganese oxide (LMO) and lithium iron phosphate (LFP). Due to the high costs of pure LCO [39], its low thermal stability and fast capacity loss at high currents [39] as well as the lifetime issues of LNO [40], mixtures of the first three materials are often used, namely lithium nickel cobalt aluminum oxide (NCA) and especially lithium nickel manganese cobalt oxide (NMC). The ratio of the materials in $\mathrm{NMC}$ can be chosen in a wide range in cell design. Yet, often a 1/3-1/3-1/3 can be found which has a similar specific energy and operation voltage to LCO at significantly lower costs. As the voltage curve of NMC is comparatively steep, the management and especially SoC estimation is comparatively easy. Moreover, no hysteresis effects have to be taken into account. LFP cells offer a higher safety due to their thermal stability and a good power capability at the drawback of a relatively low average potential and therefore also energy density [39]. Summing up, it can be stated that NMC, LFP and LTO are particularly of potential interest for use in public transport. Many current systems on the market in public transport feature NMC cells due to the superior energy density in comparison to LFP and LTO. The two reference systems, SEB and Smart Wheels, were also built using NMC cells mainly due to that positive effect. However, the BYD e-bus features LFP cells, and large field tests in Munich and Vienna are also run with this chemistry. Even LTO cells can already be found, for example with the Proterra's EcoRide BE35 as well as Microvast, a manufacturer of LTO packs that is currently running buses in China, Hongkong, London and in The Netherlands.

The performance and especially the lifetime of cells with identical size and chemistry can widely differ. This risk is assessed through aging tests on a battery test bench with the corresponding application load profile as well as general parameterization and aging tests. During the cell selection process, suitable lithium-ion cells with a high charging power capability in case of a fast charging strategy have to be identified first. The resulting power profile of the energy consumption simulation can be downscaled to cell level and extended by a subsequent charging according to the chosen strategy. This procedure represents the application sufficiently and ensures realistic test conditions. Furthermore, the test results 
provide information about the cell performance at its end-of-life, which has to be taken into account as a worst-case scenario in the dimensioning of the cooling system.

Regarding the detailed aging analysis, calendric as well as cyclic aging have to be considered individually and added up to obtain the overall aging depending on the usage scenario [41]. Usually several cells are tested per test condition in order to take the cell spread into account [10]. In calendric aging, the influence of temperature and storage $\mathrm{SoC}$ are analyzed in particular. For cyclic aging, the $\mathrm{DoD}$, the mean SoC and temperature and current in both, charging and discharging, have to be considered [20]. In Figure 8, an example of an aging test analyzing the $\mathrm{DoD}$ at a $2 \mathrm{C}$ cycling at $30{ }^{\circ} \mathrm{C}$ is shown. The tested cells are Kokam pouch cells such as those used in Smart Wheels and SEB. It shows the evident impact of the DoD on the aging speed. Yet even at 80 percent DoD, a sufficient cycle lifetime for public transport was achieved.

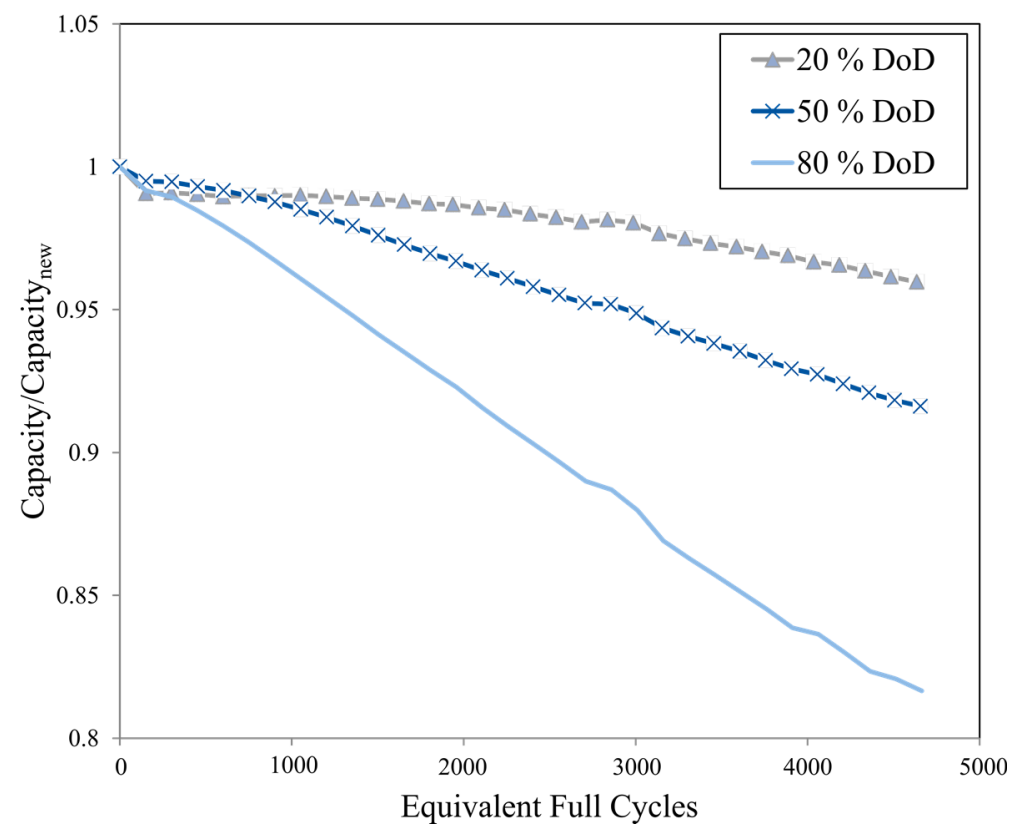

Figure 8. Reference aging analysis of a Kokam pouch cell.

Regarding the cooling demand, the cell geometry has to be taken into account. Cells types are divided into round cells, prismatic cells and pouch bag cells, which are shown in Figure 9. While pouch cells are relatively easy to cool due to their large surface area and the thin housing, the predominant direction of the thermal conduction of round cells is axial $[42,43]$. Moreover, a large temperature gradient can be found in some of the axial cells due to the connection to the terminals [44]. Therefore, cooling via the surface is not only more difficult due to the shape but also less effective. Regarding prismatic cells, one might assume that sufficient cooling can always be achieved via the ground plate. However, the shape of the jelly roll has to be taken into account. In some prismatic cells the jelly roll is positioned at a 90-degree angle to the tabs and therefore no good thermal linkage to the ground plate can be assumed, as the radial thermal conduction of the roll is relatively small and only a thin part of the cell is in close contact with the housing in that case, as can be seen by the internal structure in Figure 9. Yet if there is a thick enough metal cell casing it can be accounted for as a compensation for the bad connection, as in that case the housing offers good thermal conductivity to the base from all sides. 


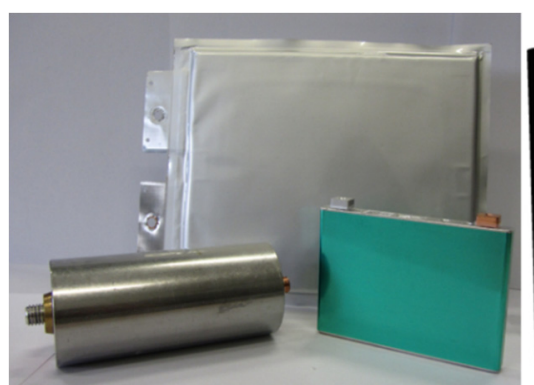

(a)

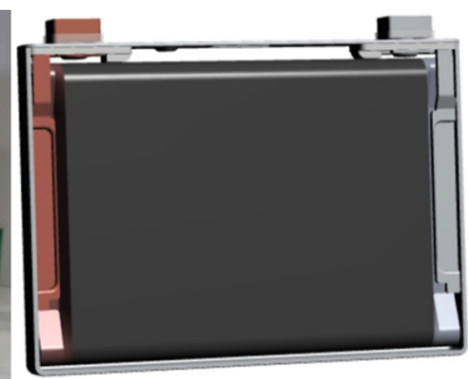

(b)

Figure 9. (a) Pouch (back), round (left) and prismatic (right) cell and (b) corresponding CAD model of the internal structure of the 5 Ah prismatic cell.

\subsection{Battery Management System}

The battery management system (BMS) for transport applications is mostly set up in a master-slave architecture as shown in Figure 10. Next to the measurement on the cell level, a measurement of the pack voltage and string currents ( $\mathrm{HV}$-interface) as well as a control of the safety devices such as the switches and precharge circuit is mandatory. Systems consisting of multiple packs are either controlled by a joint master or operated completely independently to expand the redundancy. The master, as the main intelligence of a battery, has various responsibilities [45]:

- Vehicle communication,

- Plausibility check of measurement values,

- Interconnection of packs,

- Control of the admissible charging power,

- Control of the switches as well as the precharge circuit,

- Adherence to threshold values such as end of (dis)charge voltages and temperatures,

- Monitoring of the state of health of the battery,

- Power prediction during operation, and

- Supervision of insulation-resistance.

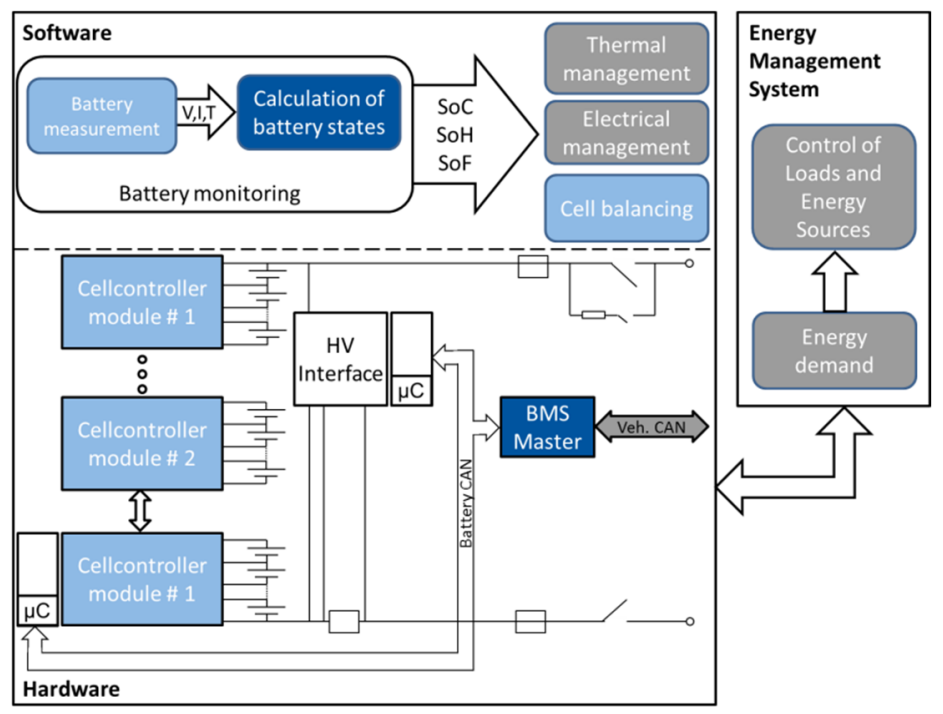

Figure 10. Structure of the battery management system on software and hardware side. 
These functions on the software side of the BMS can be structured according to Figure 10. Battery states such as state of charge ( $\mathrm{SoC})$, state of health $(\mathrm{SoH})$ and state of function (SoF) are calculated by the measured current, voltage and temperature of the single cells. They are needed for the further electrical and thermal management of the battery as well as the balancing routines which are needed to minimize the spread between the single cells in a serial connection. Regarding SoC estimation, different techniques are mostly combined, consisting of a full charge detector, an open circuit voltage module (see e.g., [46]) as well as an ampere hour balancing routine. The state of charge is a critical factor when it comes to electric vehicles, as a lot of the further management strategies are based on it. An example for this is the power prediction being directly dependent on the remaining SoC. With a faulty SoC showing high values, the voltage can drop significantly during a high power discharge pulse. By this means, a cut off voltage can be reached, resulting in a limitation of the available power which might not fulfill the actual demand anymore. Keeping an accurate SoC estimation over a long time period is challenging, especially if only rare full charge events are present, allowing for a reset of the algorithms. For electric buses this is an issue, especially if only fast charging is applied without a regular standard charge during night. Hence, sophisticated methods to improve accuracy are needed. This can be done, e.g., by Kalman filters [47]. A detailed overview and comparison of further existing methods is provided by [48].

For each cell in the series connection, a voltage measurement and balancing architecture is needed. These cell controller modules (light blue) are responsible for the preprocessing of the measured data (cell voltages and temperatures). They are usually located in close physical proximity to the actual battery modules/cells to minimize the length of the measurement cables. The importance of the low level data preprocessing has to be emphasized, as there are wide spectra of noise. In particular, high currents in combination with the short switching times of the inverter result in a strong electro-magnetic field and a wide spectrum of possible emissions [49]. Hence, suitably adapted lowpass filters for both temperature and voltage measurement are needed to limit measurement inaccuracies. As shown in [50], a low filtering has a huge impact on the measurement values and limits the usability of the data and therefore the reliability and stability of the overall system. In this context, a tradeoff between the generally desired high dynamic of the measurement and the filtering has to be found for each signal individually. Voltage and current values are needed at a high sampling rate whereas a higher time constant is admissible for the temperature values to limit the interferences due to the converters. The communication of these values between cell controller modules and BMS master is usually done by a battery internal CAN bus or alternative bus protocols such as $\mathrm{I}^{2} \mathrm{C}$. Regarding the temperature measurement, it is furthermore important to mention that usually the cell monitoring chips offer less temperature channels than voltage measurements. Moreover, measuring the temperature of each cell would be quite costly. Hence, in current battery systems, not all cell temperatures will be monitored individually. By thermal models of the packs the single cell temperatures can be calculated in normal operation mode by the existing temperature measurements. This, however, does not allow for a safe detection of a malfunction within a battery system leading to the possible risk of a thermal runaway. In order to prevent that, two different strategies shall be proposed. To simply detect already a temperature higher than a given threshold without measuring the actual temperature of each cell, a bimetal circuit can be used [50]. This comes at comparatively low additional effort and costs. Another more complex method is to use the already existing cell controller modules to detect the temperature by a correlation to the electrical impedance that can be measured within certain limitations, also online. 
Next to the voltage measurement, the balancing is either realized by a passive or active balancing method. Passive balancing is realized by discharging the cells, having a higher voltage than a specific threshold, by a resistor and thus converting electrical energy to heat. Active balancing in contrast shifts the energy from one cell in the string to the others or another specific cell via an active converter [51,52] and is therefore more efficient than passive cell balancing. Whether an active balancing is beneficial on system level depends on the one hand on the aging spread of the cells and on the other hand on the usage scenario. The higher the aging spread the higher the benefit of the active system as it enables to even balance the cell voltages not only during the full charge but also during the discharge phase. This goes along with the dependence on the usage scenario as it will be especially of interest to balance also during discharge if full cycles are applied to the battery as this results in a higher possible driving range.

\subsection{Passive Components}

All parts within a battery system that do not directly add to the energy and power density are referred to as passive components. Next to the already discussed BMS, the safety devices in particular have to be considered as they are not negligible regarding weight and costs of the system. These safety systems (see Figure 10) usually consist of two main high-voltage switches (both poles of the battery) and a precharge circuit to disconnect the battery from the rest of the drive train in case of emergency and during standstill. The precharge circuit is needed on reconnecting as otherwise a high inrush current would occur due to the voltage difference between battery and DC-link. The input capacitors of the converter cannot withstand the high current, but also the switches and the cells themselves are not rated for such high currents even though it is only a pulse load [50]. The precharge resistor can be sized by the input capacitance and the time it takes until the current drops under a boundary value that is admissible for the whole circuit. Moreover, the peak and overall power that have to be dissipated by the resistor have to be considered in the design process. Additionally to the interruption of the circuit by switches, a fuse is added on one or both poles to prevent the battery from further damage in case of an external short. Mostly, the device for evaluating the insulation resistance is also fitted into the battery and a service plug is added to assure lower voltages e.g., for maintenance periods.

In Figure 11 the weight ratio of the components of the Smart Wheels' battery system (see Figure 6) is given. It can be seen that the cells account for approximately two thirds of the overall weight, which is 430 kilograms for around 44 kilowatt-hours. With a gravimetric energy density of 100 kilowatt-hours per kilogram, an equal energy density to that of the BMW i3 was achieved [53]. As the pack is mounted under the floor, the housing is also quite massive, and due to the fast charging, a liquid cooling system is needed, adding additional weight as well. The cell connectors account for almost 6 percent of the weight. However, this could be greatly reduced by welding the cells in mass production [22]. Yet the passive components account for 4 percent of the overall system, with the switches and fuses being the heaviest components. This weight greatly depends on the current rates. Moreover, it has to be kept in mind that when distributing the system in several packs especially the heavy components such as fuses and switches are needed in every pack. Hence, a tradeoff has to be found between reliability and flexibility on the one hand and system weight and achievable energy density on the other. To reduce needed space, weight and costs of the passive components, they should be directly integrated in the battery pack instead of a separate housing. This improves safety while keeping the switches in the closest possible proximity 
to the battery cells and ensuring there are no additional live parts within the vehicle in case of an emergency [50].

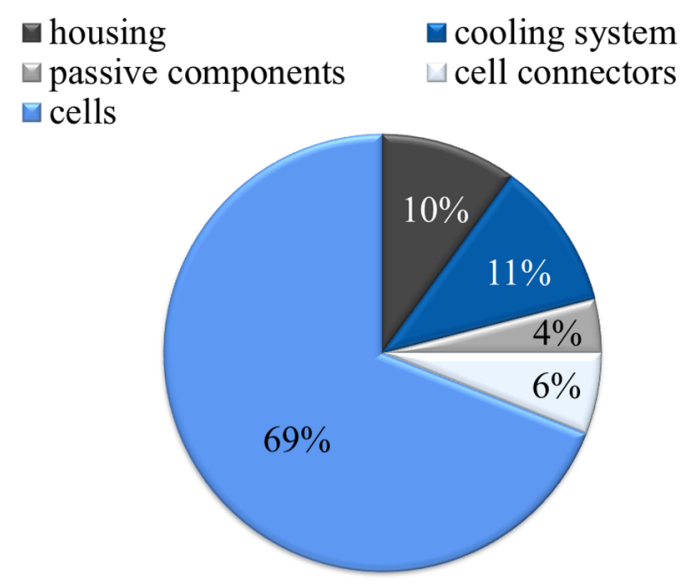

Figure 11. Weight distribution of the battery system in Smart Wheels.

Another important point regarding the passive components is their heat generation and how they might influence each other. Switches in particular, which are normally held actively shut by an electromechanic coil system, emit a significant amount of heat as can be seen in Figure 12. In the first $10 \mathrm{~min}$ the battery system was operated but in standby, so no load was drawn. Still, the switch temperature raised around 7 degrees Celsius as the switches were actively held shut. At the same time, fuses, which are normally melting fuses with a distinct tripping characteristic, are directly influenced by a rise in ambient air and should therefore not be sized with too narrow a margin or placed in close proximity to the switches. In the figure it can be seen that during load, the temperature of the fuse shows the strongest increase, but it cools down rapidly again in the following standstill period. In a sealed environment, care has to be taken in terms of how the heat can be dissipated by, e.g., only mounting the component on materials with good thermal conductivity.

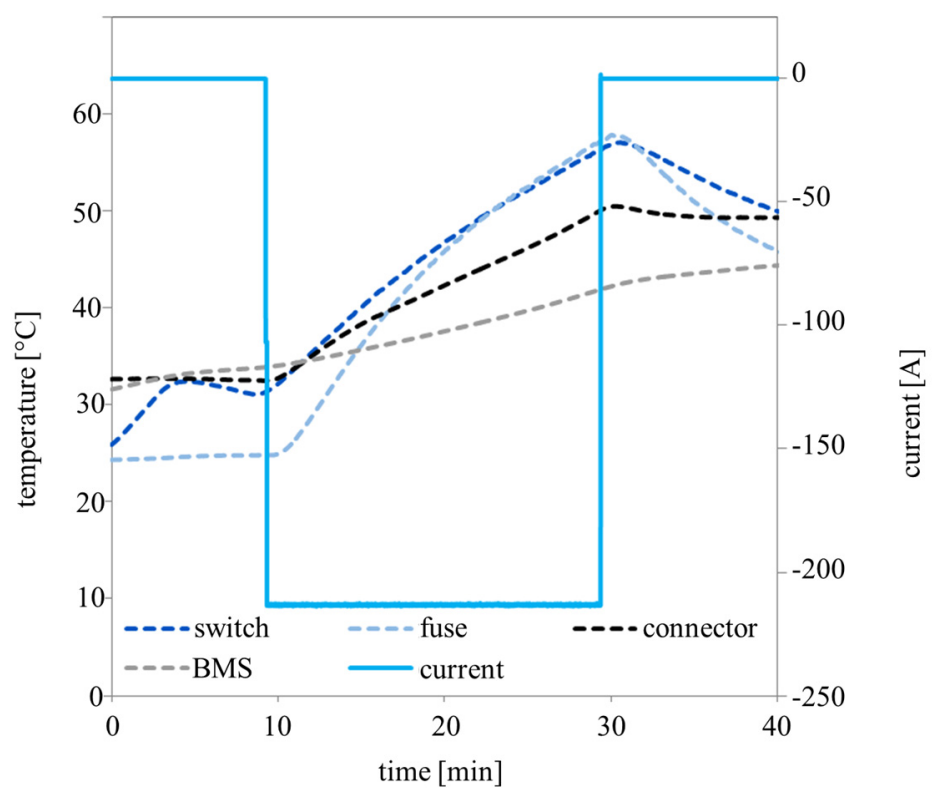

Figure 12. Heat up process of different pack components under load. 


\subsection{Thermal Management}

Availability of the vehicle is of great importance in public transport. Excessively high or low temperatures for the battery can be potential limiting factors in that regard. At the same time, the usage scenario in a continuous full day operation in combination with fast charging is quite demanding in terms of thermal management. Therefore, an application-designed cooling system is mandatory. Moreover, as explained in Subsection 4.1 of this section, in contrast to common vehicle applications, the full life cycle of the batteries will be exploited. Hence, realizing a lower average operation temperature has a direct impact on the system lifetime.

The design goals of the cooling system have to fulfill several tasks:

- Lower the maximum temperature to reduce aging,

- Prevent deep temperature charging to avoid Lithium-plating,

- Limit the temperature gradient within the cell to prevent uneven usage of the material within the cell, and

- Limit the temperature gradient within the pack to minimize the aging diversification of the cells.

As shown in [35] the aging spread of the cells is quite high and cannot be limited by sorting the cells by their initial capacity. This effect is even more enhanced by a temperature gradient among the cells used as the Arrenhius equation [54]. According to a rule of thumb, a doubling of aging results from a ten degree temperature increase. Therefore, it is advised rather to go for the smallest possible pack gradient instead of aiming to decrease the peak temperature a bit further in consideration of the design tasks. Liquid cooling topologies favorable for this are bifilar cooling or a parallelized cooling structure with adjusted flow rates in the different channels [50].

In Figure 13 it can be seen how the gradient among the cells of the two Smart Wheels' packs changes during two hours of operation in cold ambient conditions. On the left hand side of the figure the temperature distribution in the mornings before operation is given. All cells have similar temperatures resulting in a normal distribution within the system. The slight existing differences can be explained by inner and outer cells. The center part of the system is still slightly warmer due to the huge heat capacity of the system and the coldest cells are located directly next to the housing as the packs are mounted underfloor. However, after $2 \mathrm{~h}$ of operation a clear separation in two groups with a delta of 1.5 to 2 degrees Celsius each can be found. This behavior can be explained by one pack being mounted at the vehicle's front axle with a higher cooling due to the air flow. In contrast, the other pack is mounted behind the rear axis and due to the shape of the vehicle under the floor mostly protected against the air flow. However, within the packs the temperature gradient could be kept small due to the bifilar cooling in the ground plate of the system. 


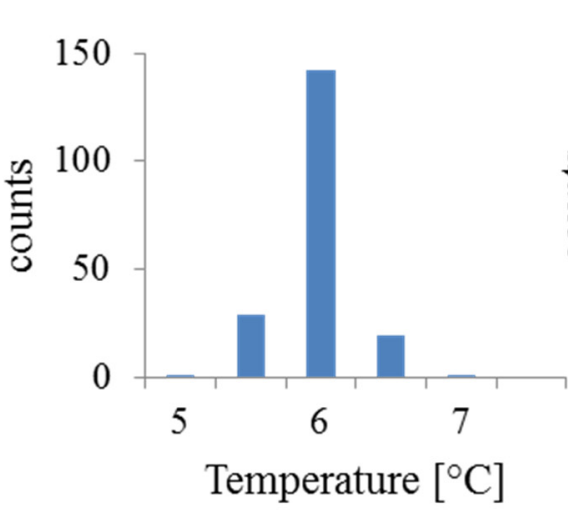

(a)

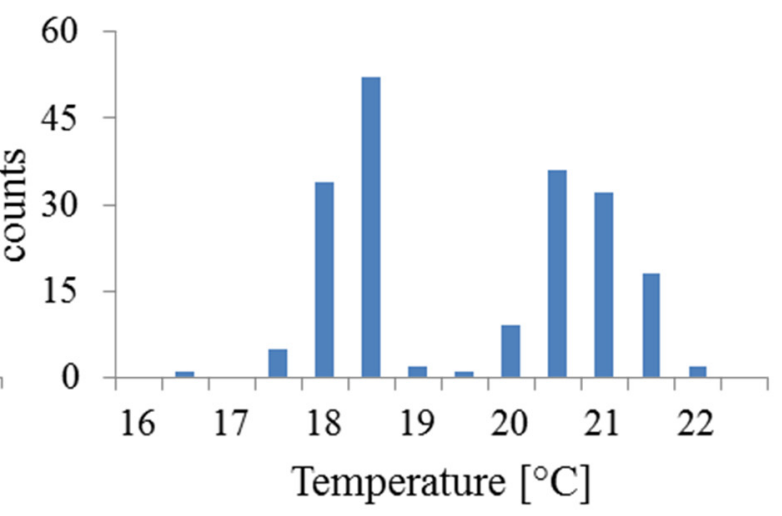

(b)

Figure 13. Temperature distribution within the two Smart Wheels' battery packs before (a) and after (b) two hours of driving.

\section{Conclusions}

In this work, an overview was given on how a successful electrification of the public bus sector can be achieved with battery-powered buses. It was shown that for an optimized system, not only the vehicle itself but also the charging strategy and the charging infrastructure have to be taken into account. A detailed knowledge of the expected load profile and usage scenario is mandatory. Within the battery system, several different topologies are conceivable depending on the cells used, offering different degrees of reliability and freedom. There is not a standard solution valid for all applications. Rather it is necessary to analyze and to design the battery system and the charging concept according to the local situation and demand. During system design it is important, after close management, to also take the rest of the passive components and the cooling into account to produce a system that is competitive with diesel buses and has a satisfactory lifespan.

\section{Acknowledgments}

This work has been kindly supported by the German Federal Ministry for Economic Affairs and Energy (BMWE) as part of the SmartWheels and econnect projects, as well as the German Federal Ministry for Education and Research (BMBF) within the SEB eÖPNV project.

\section{Author Contributions}

The layout of the prototype system within Smart Wheels was done by Susanne Rothgang. She also carried out the experiments concerning it and the build-up phase. Matthias Rogge simulated the energy consumption and developed tools for it. Jan Becker contributed to the multi-pack architecture. Dirk Uwe Sauer contributed to all of the parts.

\section{Conflicts of Interest}

The authors declare no conflict of interest. 


\section{References}

1. Commision of the European Communities. Results of the Review of the Community Strategy to Reduce $\mathrm{CO}_{2}$ Emissions from Passenger Cars and Light-Commercial Vehicles; Commision of the European Communities: Bruessels, Belgium, 2007.

2. Hartmann, N.; Oezdemir, E.D. Impact of different utilization scenarios of electric vehicles on the German grid in 2030. J. Power Sources 2011, 196, 2311-2318.

3. Vetter, J.; Novák, P.; Wagner, M.R.; Veit, C.; Möller, K.-C.; Besenhard, J.O.; Winter, M.; Wohlfahrt-Mehrens, M.; Vogler, C.; Hammouche, A. Ageing mechanisms in lithium-ion batteries. J. Power Sources 2005, 147, 269-281.

4. Käbitz, S.; Gerschler, J.B.; Ecker, M.; Yurdagel, Y.; Emmermacher, B.; André, D. Cycle and calendar life study of a graphite LiNi1/3Mn1/3Co1/3O2 Li-ion high energy system. Part A: Full cell characterization. J. Power Sources 2013, 239, 572-583.

5. Follmer, R.; Gruschwitz, D.; Jesske, B.; Quanst, S.; Lenz, B.; Nobis, C.; Köhler, K.; Mehlin, M. Mobilität in Deutschland 2008: Ergebnisbericht; Struktur-Aufkommen-Emissionen-Trend; Ergebnisbericht,infas, dlr: Berlin/Bonn, Germany, 2010. (In German)

6. United Kingdom Department for Transport. Collection-Transport Statistics Great Britain. Available online: http//www.gov.uk/government/collections/transport-statistics-great-britain (accessed on 14 April 2015).

7. Viswanathan, V.V.; Kintner-Meyer, M. Second use of transportation batteries: Maximizing the value of batteries for transportation and grid services. Trans. Veh. Technol. 2011, 60, 2963-2970.

8. Zhou, C.; Qian, K.; Allan, M.; Zhou, W. Modeling of the cost of EV battery wear due to V2G application in power systems. IEEE Trans. Energy Convers. 2011, 26, 1041-1050.

9. Peterson, S.B.; Apt, J.F.; Whitacre, J. The economics of using plug-in hybrid electric vehicle battery packs for grid storage. J. Power Sources 2010, 195, 2377-2384.

10. Ecker, M.; Nieto, N.; Käbitz, S.; Schmalstieg, J.; Blanke, H.; Warnecke, A.; Sauer, D.U. Calendar and cycle life study of $\mathrm{Li}(\mathrm{NiMnCo}) \mathrm{O}_{2}$-based 18650 lithium-ion batteries. J. Power Sources 2014, 248, 839-851.

11. Kalinowska, D.; Kloas, J.; Kuhfeld, H.; Kunert, U. Akualisierung und Weiterentwicklung der Berechnungsmodelle für die Fahrleistungen von Kraftfahrzeugen und für das Aufkommen und für die Verkehrsleistung im Personenverkehr (MIV); DIW Berlin: Berlin, Germany 2005. (In German)

12. ISEA \& EBusPlan. LCC Calculator. Available online: http://www.ebusplan.com/en/calculator/ (accessed on 1 June 2015).

13. Schwarzer, V.; Ghorbani, R. Drive cycle generation for design optimization of electric vehicles. Trans. Veh. Technol. 2013, 62, 89-97.

14. Wu, J.; Li, K.; Jiang, Y.; Lv, Q.; Shang, L.; Sun, Y. Large-scale battery system development and user-specific driving behavior analysis for emerging electric-drive vehicles. Energies 2011, 4, 758-779.

15. Sinhuber, P.; Rohlfs, W.; Sauer, D.U. Study on power and energy demand for sizing the energy storage systems for electrified local public busses. In Proceedings of the 2012 IEEE Vehicle Power and Propulsion Conference (VPPC), Seoul, Korea, 9-12 October2012; pp. 315-320. 
16. BYD. BYD Electric Bus Introduction. Available online: http://www.byd.com/na/auto/ ElectricBus.html (accessed on 29 June 2015).

17. Legrand, N.; Knosp, B.; Desprez, P.; Lapicque, F.; Rael, S. Physical characterization of the charging process of a Li-ion battery and prediction of Li plating by electrochemical modelling. J. Power Sources 2014, 59, 208-216.

18. Winter, M.; Brodd, R.J. What are batteries, fuell cells, and supercapacitors? Chem. Rev. 2004, 104, 4245-4269.

19. Khaligh, A.; Zihao, L. Battery, Ultracapacitor, fuel cell, and hybrid energy storage systems for electric, hybrid electric, fuell cell, and plug-in hybrid electric vehicles: State of the art. Trans. Veh. Technol. 2010, 59, 2806-2814.

20. Wang, S.; Zhao, L.; Su, X.; Ma, P. Prognostics of lithium-ion batteries based on battery performance analysis and flexible support vector regression. Energies 2014, 7, 6492-6508.

21. Rothgang, S.; Baumhöfer, T.; van Hoek, H.; Lange, T.; de Doncker, R.W.; Sauer, D.U. Modular battery design for reliable, flexible and multi-technology energy storage systems. Appl. Energy 2015, 137, 931-937.

22. Rothgang, S.; Lunz, B.; Laresgoiti, I.; Geulen, G.; Homann, J. HV Traction Battery: From Layout to Realization; Electric Vehicle Symposium: Los Angeles, CA, USA, 2012.

23. Wang, J.; Liu, P.; Hicks-Garner, J.; Sherman, E.; Soukiazian, S.; Verbrugge, M.; Tataria, H.; Musser, J.; Finamore, P. Cycle-life model for graphite-LiFePO 4 cells. J. Power Sources 2011, 196, 3942-3948.

24. Schein, H.; Holl, K. Vorstellungen und Erwartungen aus Sicht der Zellhersteller; Batterieforum Deutschland: Berlin, Germany, 2014. (In German)

25. Hummel, P.; Houchois, P.; Dewhurst, J.; Gandolfi, A.; Hunt, S.; Lesne, D.; Oldfield, S.; Leitch, D.; Dumoulin-Smith, J.; Gilbert, T.; et al. Global Utilities, Autos \& Chemicals. Will Solar, Batteries and Electric Cars re-Shape the Electricty Systems? UBS Research: Zurich, Switzerland, 2014.

26. German Association of the Automotive Industry (VDA). Annual Report 2012; VDA: Berlin, Germany, 2012.

27. EU Transport in Figures 2012; Publications Office of the European Union: Luxembourg, Luxembourg, 2012.

28. Zhang, T.; Chen, W.; Han, Z.; Cao, Z. Charging scheduling of electric vehicles with local renewable energy under uncertain electric vehicle arrival and grid power price. Trans. Veh. Technol. 2014, 63, 2600-2612.

29. Jin, C.; Tang, J.; Ghosh, P. Optimizing electric vehicle charging: A customer's perspective. Trans. Veh. Technol. 2013, 62, 2919-2927.

30. Bombadier. Bombardier Primove. Available online: http://primove.bombardier.com/products/ charging.html (accessed on 29 June 2015).

31. Müller-Hellmann, A. Vom aschenbrödel zum rückgrat multimodaler E-mobilität-infrastrukturen kommunaler gleichstrombahnen beflügeln nationalen entwicklungsplan elektromobilität. Der Nahverk. 2012, 12, 15-20. (In German)

32. Siemens. Available online: http:/www.mobility.siemens.com/mobility/global/SiteCollectionDocuments/ en/road-solutions/urban/ebus-ebrt/ebus-wiener-linien-brochure-en.pdf (accessed on 29 June 2015). 
33. Schunk. Charging Pantograph SLS101. Available online: http://www.schunk-sbi.com/ sixcms/media.php/1973/SLS101-chargingPantograph.pdf (accessed on 14 April 2015).

34. Uddin, K.; Picarelli, A.; Lyness, C.; Taylor, N.; Marco, J. An acausal Li-ion battery pack model for automotive applications. Energies 2014, 7, 5675-5700.

35. Baumhöfer, T.; Brühl, M.; Rothgang, S.; Sauer, D.U. Production caused variation in capacity aging trend and correlation to initial cell performance. J. Power Sources 2014, 247, 332-338.

36. Schüssler, M.; Allmann, C.; Wein, M.; Landgraf, J.; Regler, C.; Schurius, M.; Gut, G.; Staats, H.; Ginsberg, S.; Hillers, T.; et al. Research Project e Performance. From Concept to Vehicle; Aachen Colloquium Automobile and Engine Technology: Aachen, Germany, 2012.

37. Mulder, G.; Omar, N.; Pauwels, S.; Meeus, M.; Leemans, F.; Verbrugge, B. Comparison of commercial battery cells in relation to material properties. Electrochim. Acta 2013, 87, 473-488.

38. Han, X.; Ouyang, M.; Lu, L.; Li, J. Cycle life of commercial lithium-ion batteries with lithium titanium oxide anodes in electric vehicles. Energies 2014, 7, 4895-4909.

39. Nitta, N.; Wu. F.; Lee, J.T.; Yushin, G. Li-ion battery materials: present and future. Mater. Today 2015, 18, 252-264.

40. Broussely, M.; Biensan, P.; Simon, B. Lithium insertion into host materials: the key to success for Li ion batteries. Electrochim. Acta 1999, 45, 3-22.

41. Hou, C.; Wang, H.; Ouyang, M. Battery sizing for plug-in hybrid electric vehicles in Beijing: A TCO model based analysis. Energies 2014, 7, 5374-5399.

42. Fleckenstein, M.; Bohlen, O.; Roscher, M.A.; Bäker, B. Current density and state of charge inhomogenities in Li-ion battery cells with LiFePO4 as cathode material due to temperature gradients. J. Power Sources 2011, 196, 4769-4778.

43. Maleki, H.; Hallaj, S.A.; Selman, J.R.; Dinwiddle, R.B.; Wang, H. Thermal properties of lithium-ion battery and components. J. Electrochem. Soc. 1999, 146, 947-954.

44. Robinson, J.B.; Darr, J.A.; Eastwood, D.S.; Hinds, G.; Lee, P.D.; Shearing, P.R.; Taiwo, O.O.; Brett, D.J.L. Non-uniform temperature distribution in Li-ion batteries during discharge-A combined thermal imaging, X-ray micro-tomography and electrochemical impedance approach. J. Power Sources 2014, 252, 51-57.

45. Xing, Y.; Ma, Eden W.M.; Tsui, K.L.; Pecht, M. battery management systems in electric and hybrid vehicles. Energies 2011, 4, 1840-1857.

46. Xing, Y.; He, W.; Pecht, M.; Tsui, K.L. State of charge estimation of lithium-ion batteries using the open-circuit voltage at various ambient temperatures. Appl. Energy 2014, 113, 106-115.

47. He, W.; Willard, N.; Chen, C.; Pecht, M. State of charge estimation for electric vehicle batteries using unscented Kalman Filtering. Microelectron. Reliab. 2013, 53, 840-847.

48. Waag, W.; Fleischer, C.; Sauer, D.U. Critical review of the methods for monitoring of lithium-ion batteries in electric and hybrid vehicles. J. Power Sources 2014, 258, 114-130.

49. Maarleveld, M.; Kreisch, K.; Kellerbauer, H.; Friedrich, K. Investigation on the propagation of disturbing pulses in traction batteries of electric and hybrid electric vehicles. In Proceedings of the 2014 International Symposium on Electromagnetic Compatibility (EMC Europe), Gothenburg, Sweden, 1-4 September 2014; pp. 391-395. 
50. Rothgang, S.; Nordmann, H.; Schaeper, C.; Sauer, D.U. Challenges in battery pack design. In Proceedings of the 2012 Electrical Systems for Aircraft, Railway and Ship Propulsion (ESARS), Bologna, Italy, 16-18 October 2012; pp. 1-6.

51. Gallardo-Lozano, J.; Romero-Cadaval, E. Milanes-Montero, M.I.; Guerrero-Martinez, M.A. Battery equalization active methods. J. Power Sources 2014, 246, 934-949.

52. Einhorn, M.; Roessler, W.; Fleig, J. Improved performance of serially connected Li-ion batteries with active cell balancing in electric vehicles. Trans. Veh. Technol. 2011, 60, 2448-2457.

53. Scott, P. The New BMW i3. Available online: http//www.asymcar.com/graphics/14/i3/bmwi3b.pdf (accessed on 14 April 2015).

54. Liaw, B.Y.; Roth, E.P.; Jungst, R.G.; Nagasubramanian, G.; Case, H.L.; Doughty, D.H. Correlation of Arrhenius behaviors on power and capacity fades, impedance, and static heat generation in lithium ion cells. J. Power Sources 2003, 119, 874-886.

(C) 2015 by the authors; licensee MDPI, Basel, Switzerland. This article is an open access article distributed under the terms and conditions of the Creative Commons Attribution license (http://creativecommons.org/licenses/by/4.0/). 